\title{
THE MOTOR DEVELOPMENT AND MOTOR SKILL LEVELS OF 6-YEAR-OLD CHILDREN FROM THE LUBLIN VOIVODESHIP
}

\author{
ELŻBIETA CIEŚLA \\ Jan Kochanowski University in Kielce, Faculty of Health Sciences, Institute of Public Health, \\ Department of Developmental Age Research
}

Mailing address: Elżbieta Cieśla, Jan Kochanowski University, 19 IX Wieków Kielc Ave., 25-369 Kielce, tel.: +48 41 3496909, fax: +48 41 3496916, e-mail: cieslaela@yahoo.com

\begin{abstract}
Introduction. The objective of the research was to assess the level of physical development and motor skills of six-yearold children from the Lublin voivodeship against the Polish population. Material and methods. The study included 2144 children, 997 girls and 1134 boys. To assess the level of physical fitness, selected, exercises from the EUROFIT test were used. In addition, children's ability to demonstrate simple motor skills during physical play and games was also assessed. The assessment involved: throwing a bag with the right hand, throwing a ball with both hands, gripping a bag with the right hand, kicking a ball with the right foot, jumping on the right leg and jumping with both feet. In addition, coordination during the exercises was evaluated. For measurement purposes, a four-point scale was used. The reference point was children from a nationwide sample. The results were statistically analyzed using the Student T-test and the nonparametric chi-square test. Results. Children from the Lublin region differ significantly in their level of physical fitness from children of the same age throughout Poland $(\mathrm{p} \leq 0.001)$. They achieved significantly lower results in tests assessing the strength of their arms, abdominal muscles and, the explosive strength of their lower limbs and in two tests evaluating speed (running speed: $\mathrm{p} \leq 0.001$, hand movement speed: $\mathrm{p} \leq 0.001$ ). Only in the test of their sense of balance, did both sexes, obtain significantly better results $(\mathrm{p} \leq 0.001)$. In addition, in the opinion of physical education teachers, children in the Lublin region exhibited significantly lower levels of skill when performing motor tasks. Conclusions. The results suggest that the motor potential of preschool children is being neglected, which seems to be indirectly caused by different factors in the external environment.
\end{abstract}

Key words: physical fitness, preschool age children, EUROFIT tests battery

\section{Introduction}

Preschoolers participate actively in the daily exercises that form a part of preschool education and establish contact with their peers on a basis that involves integrating various developmental spheres, including psychological, social, physical and motor-skill development. The mutual integration of these spheres enables children to receive and process stimuli in a coordinated, planned and deliberate manner. It also enables them to acquire and perfect practical skills connected with play and various athletic forms. Possessing an adequate range of and high potential for motor skills also allows children to quickly establish contact with their peers and to participate more fully in organized exercises and in spontaneous play in peer groups [1].

Motor skills and coordination are an absolutely essential part of a child's skill set, especially in critical situations, such as when changing schools (transition from preschool to school) or beginning one-year preparations for school-based education in early education situations and when being brought up at home. These skills are especially important given that the process by which a six-year-old adjusts to new conditions depends on how much the child is capable of. Children with lower coordination potential and a smaller set of motor skills will take longer to adapt to school requirements and to adjust to their peer group [2]. On the other hand, excessive mobility coupled with a lack of concentration may make it difficult for them to acquire the new skills mandated by the educational program [1].

A child's level of physical fitness and set of motor skills also depends on the domestic, socioeconomic and cultural environment in which the child is raised [3]. However, it is clear that microeconomic and cultural indexes do not exert a direct influence on a child's motor-skill development level. According to Bielicki and Waliszko [4], their influence is based on the fact that the abovementioned social situations are most frequently accompanied by differences in the living environment that are important for the development of motor skills. These include: hygiene level, food quality, manner of spending free time and choice of physical activity selected jointly by parents and children. It is important that the child's family and immediate environment provide positive models of healthy behavior. Combining all of the abovementioned factors for a given area yields a picture of how a person functions in a given ecological niche [5]. Modifications in this area can also lead to changes in how an individual functions, especially for males, who are considered more ecosensitive. It can be assumed that the residential region defined by the voivodeship constitutes a unique niche in which individuals live and work under specific socioeconomic and cultural conditions. For example, if a region has a lower development rate, a higher unemployment rate and a lower level of education and household budget, this can influence parameters that characterize family life in households where children are being raised. These observations are confirmed by numerous auxological studies showing that 
a rural environment and a lower education level lead not only to a lower level of physical fitness, but also to larger body mass and BMI [6, 7]. Not does this kind of environment support the development of proper attitudes towards physical culture in the broad sense, including pursuit of additional activities, proper diet and looking after one's health [8]. However, urbanized and urban environments, by offering a broader selection of additional physical activities and a range of playgrounds and specialized sites designed to encourage children to play spontaneously, provide a higher degree of support for children and young people's functional development than a rural environment.

These observations are borne out by the functional development levels of children from eastern voivodeships, including the Lublin voivodeship, as compared to their peers from highly industrialized regions or to a nationwide sample from all over Poland [9]. Given that Poland exhibits regional differences with regard to economic and financial options, it would seem to be important to monitor motor development, which is considered one of the basic health indexes, especially during the preschool and primary school period. A reliable diagnosis allows inequities rooted in Polish cultural, social and economic differences to be eliminated depending on the child's place of residence during his or her school years. Consequently, the goal of the study was to assess the physical development and motor skill level of six-year-old children from the Lublin voivodeship as compared to the national population. The study assumed that the level of physical development exhibited by the study group would be below average.

\section{Material and methods}

The studies were conducted in 2006 as part of a national research program entitled "The Six-Year-Old Child About to Start School”. This program was co-financed by EU and national funds within the framework of the European Social Fund. The sample size was representative, it was based on a random selection of 10\% of children born in 1999 and 2000. A stratified sampling was also used. Children were selected based on the following schema: region expressed in terms of voivodeship, type of residence (urban/rural), and type of school attended (school/preschool) during a one-year school preparatory program.

The study was conducted from March to May. Analysis of the study involved 2131 children, 997 female and 1134 male, who took a complete battery of tests intended to measure their physical fitness and motor skills. The average age was 6.3 years $\left(s_{d}=0.293\right)$. In assessing the level of physical fitness, selected tests were applied from the EUROFIT test battery. Studies were conducted of: overall equilibrium (standing on one leg), hand movement rapidity (tapping circles), abdominal strength (30 seconds of sit-ups), flexibility (seated toe-touch test), arm strength (hanging from a bar with arms straight), running speed and dexterity (shuttle run 10x5 m). The test involving hanging from a bar with arms straight was simplified, because a large percentage of the children had problems hanging from the bar with arms bent. Furthermore, children's ability to demonstrate simple motor skills during physical play and games was also assessed. Tests were conducted on their ability to: toss a bag with their right hand, throw a ball with both hands, grasp a bag with their right hand, kick a ball with their right foot, jump up and down on their right foot, jump with both feet. Additional assessment involved measuring coordination while performing exercises. Measurements were taken on a scale of 1 to 4 , with 1 being the best execution of an exercise and 4 meaning that the child was unable to perform the exercise. The evaluations were performed by properly trained physical education teach- ers (2 teachers). The competent expert opinion method was applied.

The results were subject to statistical analysis. Simple statistical characteristics were calculated. The T-Student test was applied in assessing differences in physical fitness levels between boys and girls, as well as between children from the Lublin voivodeship and a nationwide sample. In assessing ability, the nonparametric chi-square was applied. The following statistical significance levels were assumed for all characteristics: $p \leq 0.05, p \leq 0.01$ and $p \leq 0.001$. Table 1 indicates significance levels between groups of children from the Lublin voivodeship and a national sample, whereas test values and significance levels for both sexes are presented in the text.

\section{Results}

As stated above, the point of reference for the analyzed data is the nationwide study published in the National Report entitled "Six-Year-Olds in Poland". Detailed comparative analysis is presented in Table 1.

Significant statistical differences between six-year-old boys and girls from the Lublin voivodeship with regard to the level of development of most of the motor skills in question were identified only in certain cases (Tab. 1).

Table 1. Characteristics of physical fitness of six-year-old children from Lublin voivodeship

\begin{tabular}{|c|c|c|c|c|c|c|c|}
\hline \multicolumn{2}{|l|}{$\begin{array}{l}\text { Physical } \\
\text { fitness }\end{array}$} & $\begin{array}{c}\text { Boys - } \\
\text { lubelskie } \\
\text { voivodeship }\end{array}$ & $\begin{array}{c}\text { Boys - } \\
\text { national } \\
\text { sample }\end{array}$ & $p$ & $\begin{array}{c}\text { Girls - } \\
\text { lubelskie } \\
\text { voivodeship }\end{array}$ & $\begin{array}{c}\text { Girls - } \\
\text { national } \\
\text { sample }\end{array}$ & $\mathrm{p}$ \\
\hline \multirow{2}{*}{$\begin{array}{l}\text { Total } \\
\text { balance } \\
\text { [n/min] }\end{array}$} & $\bar{x}$ & 13.03 & 15.52 & \multirow{2}{*}{0.001} & 13.13 & 14.73 & \multirow{2}{*}{0.001} \\
\hline & $S_{d}$ & 7.85 & 7.20 & & 7.35 & 7.24 & \\
\hline \multirow{2}{*}{$\begin{array}{c}\begin{array}{c}\text { Arm } \\
\text { movement }\end{array} \\
\text { speed [sec] }\end{array}$} & $\bar{x}$ & 25.37 & 24.33 & \multirow{2}{*}{0.001} & 25.71 & 24.79 & \multirow{2}{*}{0.001} \\
\hline & $S_{d}$ & 5.12 & 24.33 & & 4.76 & 5.67 & \\
\hline \multirow{2}{*}{$\begin{array}{l}\text { Flexibility } \\
{[\mathrm{cm}]}\end{array}$} & $\bar{x}$ & -0.10 & 0.63 & \multirow{2}{*}{0.001} & 1.31 & 2.07 & \multirow{2}{*}{0.001} \\
\hline & $S_{d}$ & 5.49 & 5.64 & & 5.21 & 5.51 & \\
\hline \multirow{2}{*}{$\begin{array}{l}\text { Explosive } \\
\text { power [cm] }\end{array}$} & $\bar{x}$ & 100.02 & 101.91 & \multirow{2}{*}{0.001} & 93.62 & 94.34 & \multirow{2}{*}{0.001} \\
\hline & $S_{d}$ & 21.09 & 20.07 & & 20.02 & 18.43 & \\
\hline \multirow{2}{*}{$\begin{array}{c}\text { Trunk } \\
\text { strength } \\
\text { [n/30 sec] }\end{array}$} & $\bar{x}$ & 9.56 & 10.53 & \multirow{2}{*}{0.001} & 9.34 & 10.02 & \multirow{2}{*}{0.001} \\
\hline & $S_{d}$ & 4.70 & 4.49 & & 4.51 & 4.40 & \\
\hline \multirow{2}{*}{$\begin{array}{c}\text { Functional } \\
\text { strength } \\
\text { [sec] }\end{array}$} & $\bar{x}$ & 19.21 & 19.98 & \multirow{2}{*}{0.001} & 18.32 & 18.80 & \multirow{2}{*}{0.001} \\
\hline & $S_{d}$ & 9.96 & 9.82 & & 9.64 & 9.60 & \\
\hline \multirow{2}{*}{$\begin{array}{c}\text { Running } \\
\text { speed and } \\
\text { agility [sec] }\end{array}$} & $\bar{x}$ & 28.58 & 26.56 & \multirow{2}{*}{0.001} & 29.03 & 27.58 & \multirow{2}{*}{0.001} \\
\hline & $S_{d}$ & 4.08 & 3.75 & & 3.91 & 3.72 & \\
\hline
\end{tabular}


They applied to: standing long jump - a test assessing the explosive force of the lower limbs $\left(t^{0}=7.665, p \leq 0.001\right)$, the seated toe-touch test - a measurement of flexibility $\left(t^{0}=6.007\right.$, $\mathrm{p} \leq 0.001$ ), hanging with arms straight - a test assessing arm strength $\left(t^{0}=-3.514, p \leq 0.001\right)$, and standing on one leg - to determine equilibrium $\left(t^{0}=2.196, p \leq 0.05\right)$. It should be pointed out that in these fitness components, boys achieved significantly higher ratings than their female peers. Girls obtained higher ratings only in the flexibility test (Tab. 1).

Children from the Lublin region differed significantly with regard to their level of physical fitness from the national sample $(\mathrm{p} \leq 0.001)$. They obtained markedly lower scores in tests assessing arm and abdominal strength, lower leg explosive power, and in the two tests measuring speed (running speed: $p \leq 0.001$; hand-movement speed: $\mathrm{p} \leq 0.001$ ). Only in the test assessing their sense of balance did both boys and girls achieve significantly higher scores $(\mathrm{p} \leq 0.001)$. Moreover, in the opinion of physical education teachers, children from the Lublin region exhibited significantly lower levels for motor activities (Fig. 1-6). In comparison to children throughout Poland, they earned markedly fewer good or very good scores, and more average and below average ones (inability to perform the activity) in all of the motor tasks under evaluation. This situation was noticeable primarily for the tests involving throwing a bag with the right hand (Fig. 2), jumping with both legs (Fig. 5) and kicking a ball with the right foot (Fig. 6). In addition, it was noted that the boys exhibited a much greater difference than the girls in the frequency of highest and lowest (inability to perform) scores as compare to the national sample.

Teachers also assessed overall motor coordination exhibited in performing all of the motor tasks (Fig. 7). As in the case of the previously analyzed motor skills, children from the Lublin voivodeship were rated lower than their peers from the national sample. Differences in score frequencies primarily involved the following categories: average and very good ratings for performing motor tasks. This phenomenon primarily applied to the group of boys.

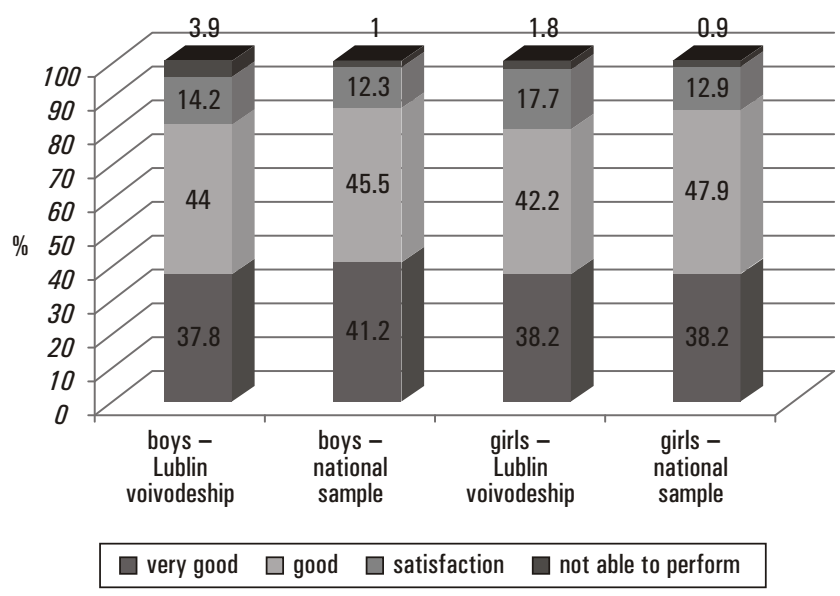

Figure 1. Motor skills evaluation of children from the Lublin voivodeship compared to nationwide sample - throw a ball with both hands $(\mathrm{p} \leq 0.001)$

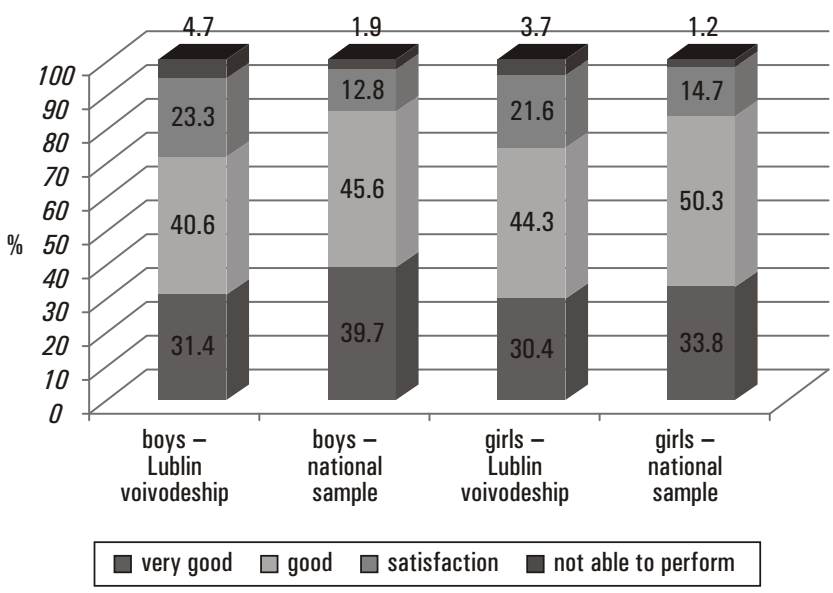

Figure 2. Motor skills evaluation of children from the Lublin voivodeship compared to nationwide sample - toss a bag with the right hand $(\mathrm{p} \leq 0.001)$

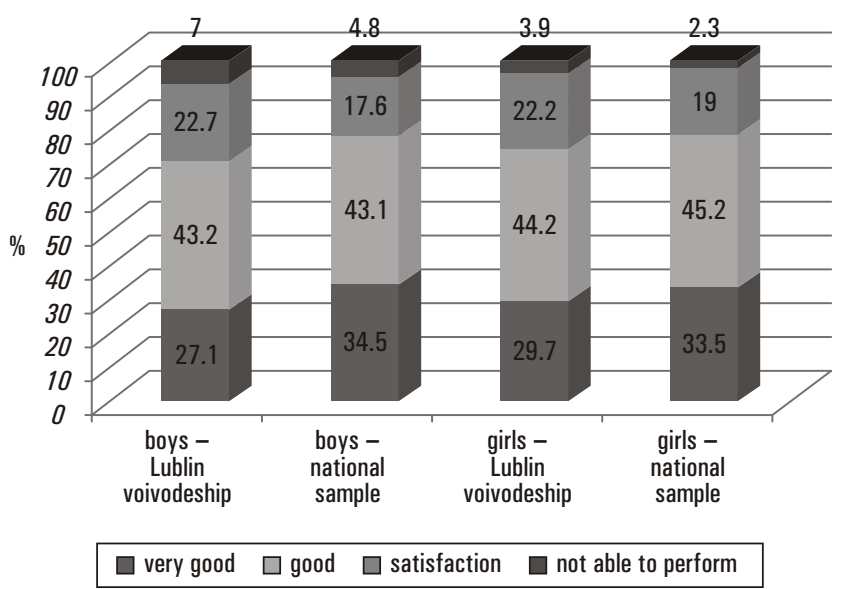

Figure 3. Motor skills evaluation of children from the Lublin voivodeship compared to nationwide sample - grasp a ball with both hands $(\mathrm{p} \leq 0.001)$

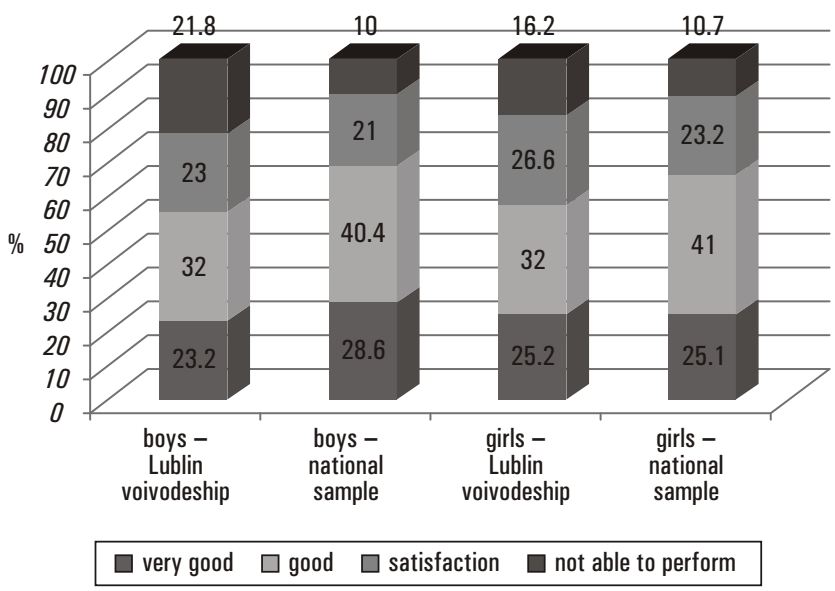

Figure 4. Motor skills evaluation of children from the Lublin voivodeship compared to nationwide sample - grasp a bag with the right hand $(\mathrm{p} \leq 0.001)$ 


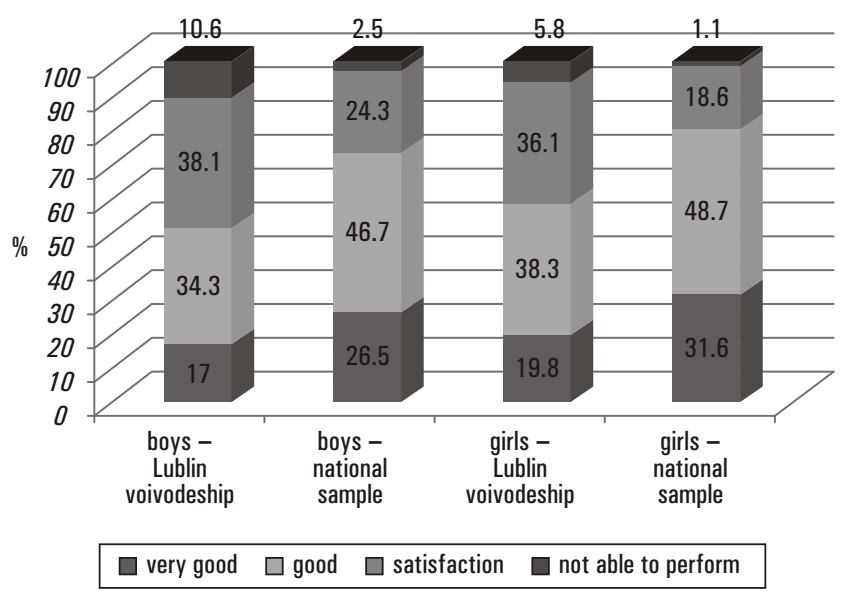

Figure 5. Motor skills evaluation of children from the Lublin voivodeship compared to nationwide sample both legs jumps $(\mathrm{p} \leq 0.001)$

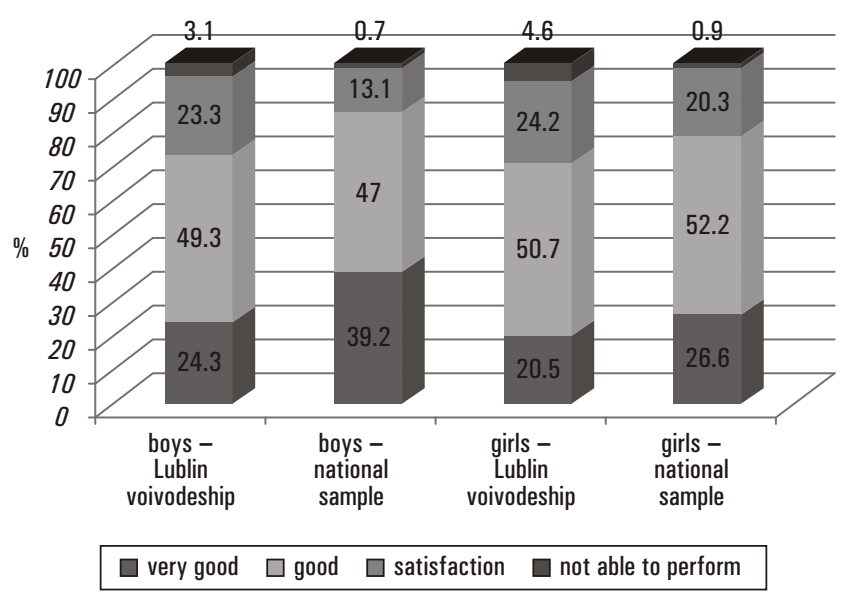

Figure 6. Motor skills evaluation of children from the Lublin voivodeship compared to nationwide sample - kick the ball with the right foot $(\mathrm{p} \leq 0.001)$

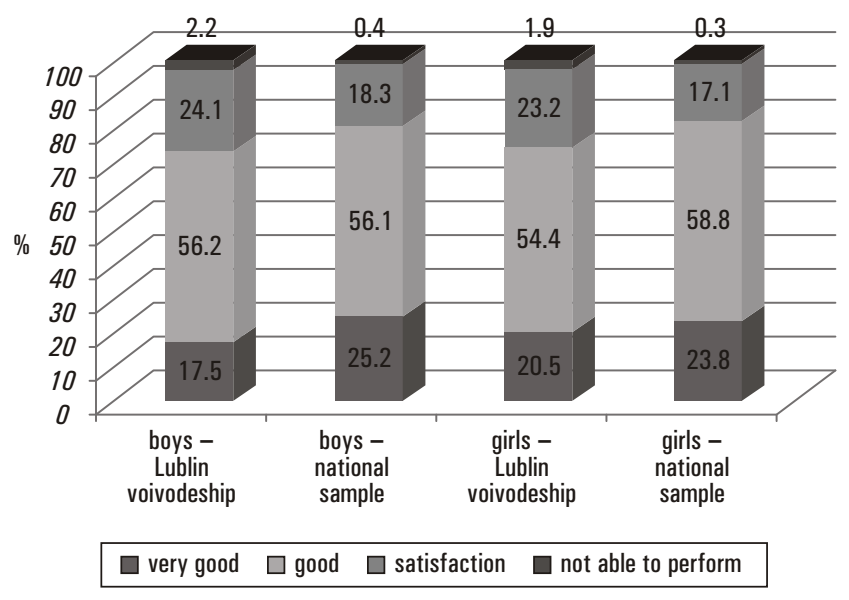

Figure 7. Motor skills evaluation of children from the Lublin voivodeship compared to nationwide sample - total coordination during exercises $(\mathrm{p} \leq 0.001)$

\section{Discussion}

This paper presents the level of motor development exhibited by six-year-old children as compared to that of their peers throughout Poland. It was assumed that children from the Lublin region may exhibit a lower level of fitness and motor skills. Research confirmed this hypothesis. It was observed that in all important aspects of fitness, with the exception of the sense of balance, children from the Lublin voivodeship exhibit a lower level of development advancement. Furthermore, the assessment of motor skills for six-year-old children from the Lublin voivodeship is significantly lower than that of their peers throughout Poland. Comparing and discussing the results is complicated by several factors, primarily because they involve younger, preschool-age children. For this reason, there are few reports dealing with the problem of fitness in a regional context or comparing various residential environments [10, 11, 12]. Another problem limiting the interpretative scope of the results involves the methodology used in conducting the study. In most cases, diverse tests are used to evaluate fitness, and although they may converge at a few points, it is not always possible to compare them due to the method of assessment [11]. Furthermore, assessments of child fitness do not yet take motor skills into account.

The level of physical fitness is a product of the state of advancement of somatic features, including height and body mass, as well as body fat percentage [13]. Thus, it may be said that the probable cause of a low level of fitness is a low level of physical development. Studies by Markowska [14] show that children from the Lublin voivodeship, as compared with the national sample, obtain lower measurements for height, body mass, chest line and waist line. Furthermore, six-year-old children from the Lublin voivodeship obtained significantly higher body fat measurements for skin folds from the biceps, triceps and below the shoulder blade. This is why lower average scores were obtained in tests correlated to body size, such as: arm strength, abdominal strength and explosive strength of the lower limbs. The improved sense of balance among children with a lower level of somatic development also confirms this dependency [15].

The observed tendency to achieve a lower level of physical fitness development and motor skills as compared to the national sample may also be conditioned by the socioeconomic conditions (SES) of families living in the Lublin voivodeship. The profile of the socioeconomic conditions noted during the children's developmental years could be based on the macroand microeconomic indexes in the Lublin region. One of these is the GDP per capita. Data from the Central Statistical Office indicates that from 2000 to 2006 the Lublin voivodeship had the lowest GDP [16]. Furthermore, other statistical sources also confirmed low earnings as compared to the national average [17]. It should be emphasized that in the Lublin voivodeship, as in other Eastern voivodeships, agriculture, food processing and rural areas comprised a relatively large share of the demographic, social and economic structure in comparison with other Polish regions [16]. During the period in question, the percentage of people residing in rural areas was $53.3 \%$ in the Lublin voivodeship, whereas the percentage was markedly lower in wealthier voivodeships in central Poland (around 33$36 \%$ ). The percentage of people working in agriculture was also relatively high in the Lublin region (38.1\%) [17]. In supplementing the analysis with socioeconomic data on the families of the test subjects, it can also be concluded that the six-yearolds came from low-income households (2142.62 PLN declared net income) as compared with regions in central Poland (e.g. the declared income in the Masovian voivodeship was on average 200 PLN higher). Only 15\% of the subjects' parents claimed that their income for the preceding month had been high, while in 
the Masovian voivodeship up to $20 \%$ of respondents voiced a positive opinion regarding their earnings. Disproportionately negative results were also obtained in connection with the father's declared level of education. Only 13.1\% of fathers claimed to possess a university education, as opposed to $16 \%$ in wealthier areas. It should be emphasized that the mothers of test subjects more frequently claimed to have a college education than the fathers, and the percentage was comparable to other regions $(20.5 \%)$. With regard to unemployment in the children's families, $6.3 \%$ of fathers and as many as $15.3 \%$ of mothers claimed to be unemployed, whereas in wealthier voivodeships this percentage was around 2 percentage points lower. The above analysis indicates that the socioeconomic structure of the families may have been responsible for creating the household environmental conditions in which the six-yearolds who participated in the study were raised.

However, it should be emphasized that the results of the study aimed at distinguishing environmental influences on fitness are not unambiguous. Research by Mleczko [18] indicates that the opposite relation holds between certain aspects of fitness and the family's SES. Children raised under belowaverage SES (socioeconomic status) conditions obtained markedly higher scores for strength and certain aspects of coordination. However, Zaradkiewicz [19] has observed that regions with poor bio-geographical and socioeconomic conditions negatively influence the development of a child's ability to move quickly. Freitas et al. [20] have also shown that speed and aspects of physical fitness are closely connected with SES, especially in the case of girls: the higher the socioeconomic (SES) index level, the higher the speed and strength levels. Peña et al. [21] arrived at different conclusions. In their studies of Mexican children they noted that children raised in an environment with lower economic standards, i.e. a rural environment, were able to move more rapidly. In Polish national studies of children ages 7-19, significantly higher running speed results were achieved by children from regions in which socioeconomic conditions and the economic situation were the lowest [22]. However, these conclusions were put forward on the basis of normalized results calculated for all test subjects.

The majority of nationwide studies conducted in Poland also indicate higher strength ratings among children and adolescents from rural areas. These results were obtained not only for preschool-aged children [23] but also for populations of school-aged children and adolescents [22, 24]. However, bearing in mind the economic indexes of the Lublin voivodeship and the socioeconomic determinants involved in biological development discussed above, it can be concluded that this phenomenon was not confirmed by the study of six-year-olds. Similar conclusions also hold for children in Mexico, where the urban rather than the rural environment was more supportive of the development of strength-related skills, even once the role of age and somatic parameters had been discounted [21].

Some studies indicate a significant correlation between the place of residence and the level of flexibility. In studies of Polish and Turkish children it has been noted that children from rural areas score higher in flexibility [22, 24, 25, 26]. However, earlier studies have indicated that the influence of the environment affected primarily male children, as the more ecosensitive [5]. Nevertheless, the six-year-old children examined in this study did not confirm the earlier conclusions.

The majority of the studies also confirm that the better living conditions provided by urban environments exert a positive influence on equilibrium scores [24]. The opposite relation was observed in the study of 6-year-old children. Children from the Lublin region, which has a typically rural character and a low level of industrialization, scored higher in tests of their sense of balance. As mentioned above, significant correlations exist between the sense of equilibrium and height and body weight, among other things [27]. Thus, it can be concluded that lower body height parameters for both sexes and lower body mass parameters and higher levels of body fat among the test subjects as compared to the national sample promote an improved sense of balance [14].

The results of the studies presented here indicate that diferences in levels of physical fitness continue to exist at the progressive development stage, with particular emphasis placed on the 6th year, when children begin the obligatory year of preschool preparatory education aimed at preparing them to enter the "0" class. Given the overall ethnic homogeneity of Polish society, the developmental disparities identified in this study probably have many causes. These include: differences in material status, the somewhat higher than average number of children and adults in the families, and the parents' slightly lower level of education as compared with Poland's wealthier regions. Another highly probable cause may be the lack of uniform access to educational institutions and forms of recreational activity, especially in rural and small-town environments. Nor should one overlook the influence of behavioral models presented by older family members, including siblings and parents, with regard to participation in physical culture. Relationships with grandparents are probably just as important, since family situations and other conditions require that grandparents take a leading role in helping raise and educate children, in shaping and determining their eating habits and in ensuring they are given adequate opportunities for daily physical activity. Constantly observing and imitating older people during a child's formative years goes a long way towards helping the child take full advantage of his or her motor potential and avoid becoming overweight or obese. This is another reason why it is important for older members of the family to initiate various forms of physical play, especially those that require developing precision, speed and various aspects of coordination. If the family provides a child with inappropriate models of physical activity and fails to draw their attention to the importance of dividing their time properly between inactive and active forms of play and recreation, it is highly likely that the child will develop motor potential that is inadequate to their needs and possibilities.

\section{Conclusions}

The disparities presented in this paper with regard to levels of physical fitness and scores on tests involving simple movements concern a relatively young group of children. It may be concluded that these disparities could become more marked at later stages of development. This is why it is important that children be encouraged from an early age to engage frequently in play and other forms of activity involving varying levels of physical movement, with particular emphasis on those forms involving moderate and intense expenditure of energy. Furthermore, it is equally important that they limit inactive forms of recreation, such as watching television or spending time on the computer or Internet. This will lead to the creation of conditions that constitute a basis for optimal development of physical fitness and motor skills. Preventative measures aimed at avoiding conditions connected with digestive disorders, including excess weight and obesity, are also important.

\section{Acknowledgements}

The results of the studies are a part of the national Polish research project: "The Six-Year Old Child About to Start School", financed by EU and Ministry of Education funds, for which the author served as coordinator of the module: "Physical 
Fitness and Motor Skills Among Children Ages 6-7”. I would like to thank the physical education teachers who conducted tests for this study in the Lublin region.

\section{Literature}

1. Osiński W. (2003). Kinesiology. Poznań: AWF. [in Polish]

2. Cieśla E., Kopik A. (2003). Profile of the physical, motor and social development of preschool-aged children from rural areas. In J. Zagórski, H. Popławska, M. Skład (Eds.), Conditions affecting the development of rural children and adolescents (pp. 487-494). Lublin: IMW. [in Polish]

3. Mleczko E., Winiarczyk T., Nieroda R. (2004). The direct and indirect influence of physical activity on the level of somatic and motor development of children and adolescents from the lesser Poland voivodeship in the light of path analysis. In J. Zagórski, H. Popławska, M. Skład (Eds.), Conditions affecting the development of rural children and adolescents (pp. 581-593). Lublin: IMW. [in Polish]

4. Bielicki T., Waliszko A. (1992). Stature upward social mobility and the nature of statural differences between social classes. Annals of Human Biology 19, 589-593.

5. Przewęda R. (1991). On social conditions affecting fitness. Wychowanie Fizyczne i Sport 4, 3-14. [in Polish]

6. Mleczko E. (2006). The biological development of rural children and adolescents in Polish auxological studies. In J. Saczuk (Ed.), Conditions affecting the development of rural children and adolescents (pp. 39-82). Biała Podlaska: AWF. [in Polish]

7. Salmon J., Timpero A. (2005). Trend's in children physical activity and weight status in high and low social-economic status areas of Melbourne, Victoria 1985-2001. Australian and New Zeeland Journal Public Health 29(4), 337-342.

8. Raczyńska B., Michalska A., Czeczelewski J., Raczyński G. (2003). The effect of socio-economic and demographic determinants on the pattern of consumption of rural adolescents. Roczniki Państwowego Zakładu Higieny 1, 65-71.

9. Popławska H. (2006). The Biological Development of Girls and Boys - from Rural Environments in Southern Podlasiein the Light of Obesity Indexes. Warsaw: Studia i Monografie AWF Warszawa. [in Polish]

10. Sekita B. (1988). Somatic Development and Physical Fitness among Children Ages 3-7 (from Research Workshops). Warsaw: AWF. [in Polish]

11. Kotarska K., Drohomirecka A. (2004). Biosocial conditions affecting the motor development of children from day-care centers and preschools in Szczecin and Stargard Szczecinski. Szczecin: Wydawnictwo Naukowe Uniwersytetu Szczecińskiego. [in Polish]

12. Asienkiewicz R. (2005). From studies of the physical and motor skill development of preschool children from Zielona Góra. Słupskie Prace Biologiczne 1, 19-25. [in Polish]

13. Żak S. (1991). Coordination Abilities among Children and Adolescents from a Major Urban Population against the Background of Somatic Conditions and Physical Activity. Kraków: AWF.[in Polish]
14. Markowska M. (2007). Physical development and motor activity. In M. Markowska (Ed.), Six-Year-Olds in Poland. Lublin Voivodeship (pp. 49-66). Kielce: Text. [in Polish]

15. Greve J., Alonso A., Bordini A.C., Camanho G.L. (2007). Correlation between body mass index and postural balance. Clinics 62(6), 717-720.

16. Statistical Yearbook. (2007). Warsaw: GUS, 459-473. [in Polish]

17. Wilkin J. (2005). Rural areas under conditions of dynamic structural change. Retrieved June 1, 2013: http://mrr.gov.pl/ rozwoj_regionalny. avaiable 13.12.2011. [in Polish]

18. Mleczko E. (1991). The Course of and Conditions Affecting Morfo-Functional Development in Children from Krakow Ages 7-14. Kraków: Wydawnictwo Monograficzne AWF Kraków. [in Polish]

19. Zaradkiewicz T. (2003). The physical fitness of boys and girls from regions throughout Poland that have varied environmental conditions (using speed as an example). In J. Zagórski, M. Skład (Eds.), Conditions affecting the development of rural children and adolescents (pp. 501-508). Lublin: IMW. [in Polish]

20. Freitas D., Maia J., Beunen G., Claessens A., Thomis M., Marques A. et al. (2007). Socio-economic status, growth, physical activity and fitness: The Madeira Growth Study. Annals of Human Biology 34(1), 107-122.

21. Pea Reyes M.E, Tan S.K, Malina R.M. (2003).Urban-rural contrast in physical fitness of school children in Oaxaca, Mexico. Annals of Human Biology 6, 693-713.

22. Przewęda R., Dobosz J.(2003). The Physical Condition of Polish Youth. Warsaw: Studia i Monografie AWF Warszawa 98, 67-83. [in Polish]

23. Momola I. (2005). Levels of motor skills mong preschoolaged children. Antropomotoryka 31(15), 47-54. [in Polish]

24. Wilczewski A., Krawczyk B., Skład M., Saczuk J., Majle B. (1996). Physical development and fitness of children from urban and rural as determined by Eurofit test Battery. Biology of Sport 13(2), 113-126.

25. Mehtap Özdirenç M., Özcan A., Akin F., Gelecek N. (2005). Physical fitness in rural children compared with urban children in Turkey. Pediatric International 47(1), 26-31.

26. Cieśla E., Domagała Z., Markowska M., Mleczko E., NowakStarz G., Przychodni A. (2012). The differences in the level of biological health indicators for 7-year-old children living in different regions of Poland. Antropomotoryka 58, 33-46.

27. Monyeki M.A., Koppes L.L.J., Kemper H.C.G., Monyeki K.D., Toriola A.L., Pienaar A.E. et al. (2005). Body composition and physical fitness of undernourished South African rural primary school children. European Journal of Clinical Nutrition 59, 877-883.

Submitted: April 22, 2013

Accepted: May 20, 2013 